\title{
Montgomery Tubercle
}

National Cancer Institute

\section{Source}

National Cancer Institute. Montgomery Tubercle. NCI Thesaurus. Code C92833.

A group of small sebaceous glands that secrete into the areolae of the mother's breast

to lubricate the nipple during breastfeeding. 